\title{
DEVELOPMENT OF A FLOATING TOW BODY FOR SHALLOW WATER BOTTOM AND SUB-BOTTOM IMAGING APPLICATIONS
}

\author{
C Kannan ${ }^{1}$, V.Ananthasubramanian ${ }^{2}$, Rhilsha $^{3}$, M A Atmanand ${ }^{4}$ \\ ${ }^{1}$ Project Scientist, Marine Sensor Systems, National Institute of Ocean Technology, Chennai, India \\ ${ }^{2}$ Professor, Department of Ocean Engineering, Indian Institute of Technology, Chennai, India \\ ${ }^{3}$ Group Head, Marine Sensor Systems, National Institute of Ocean Technology, Chennai, India \\ ${ }^{4}$ Director, National Institute of Ocean Technology, Chennai, India
}

\begin{abstract}
A floating tow body which can be towed at a speed range of 2-6 knots with a pay load of $50 \mathrm{~kg}$ is designed and tested as part of the development of a Buried Object Location Sonar (BOLS) for shallow water imaging application. In this paper the results of extensive towing tank measurements of a floating tow body with the diamond and a cross shaped bow are presented and compared. A cross shaped bow with a stream lined body shape is adopted for the floating tow body for minimizing the drag as well as the turbulence during the tow. Both the bow shape as well as the dimensions of the body is optimized based on the towing tank experimental results so that the body can be towed smoothly with minimum turbulence to avoid acoustic noise generation during the SONAR tests. An iterative experimental procedure is carried out in finalizing the dimensions and the shape of the tow body.
\end{abstract}

Keywords: Floating tow body, bow shape, towing test.

\section{INTRODUCTION}

Buried Object Location Sonar (BOLS) system developed by National Institute of Ocean Technology (NIOT) primarily is a tow body consisting transducers, electronic hardware and deck side data processor. The tow body comprises an acoustic transmitter, four linear receiver hydrophone arrays, two electronic bottles to accommodate all transmitter and receiver electronics, data acquisition system, motion sensor unit, GPS receiver, power supplies, power amplifier, etc. Tow body (housing all the components), has to be towed at a speed of 2-6 knots with minimum turbulence. Usually a depressor unit is used to submerge neutrally buoyant tow bodies when it is being towed as a part of imaging applications [1]. A floating tow body is designed so that it could avoid the necessity of the depressor unit while towing. The body should be positively buoyant and should float at about half the draft so that the head mass of the projector (transmitter) and all the hydrophones are always underwater during the operation. All the electronic components are kept inside two electronic bottles, which are placed on top of the tow body. GPS module is kept at a suitable height so that it will be free from waves and other disturbances. The entire system is connected to the desk through an underwater electro mechanical tow cable, which will tow the body at a speed of 2-6 knots as well as supply the required power to the electronic unit on the tow body. The floating tow body is hydro dynamically designed to tow smoothly and to ride swell and waves without tilting to avoid acoustic noise generation during the operation of the system. With this background and given the pay load conditions, an iterative process is carried out in finalizing the dimensions and the shape of the tow body.

\section{DEVELOPMENT OF THE INITIAL TOW BODY}

First a tow body of the size $1.25 \mathrm{~m} \times 1 \mathrm{~m} \times 0.30 \mathrm{~m}$ is designed and fabricated with a diamond like bow shape and a perspective view of the tow body with all the components is shown below in Fig -1. An acoustic transmitter, which is the heaviest component on the tow body is kept at the middle of the body and four linear hydrophone arrays are kept at the bottom of the body at equal spacing so that all the hydrophone and the head mass of transmitter are always underwater, similar to a 3D chirp sub-bottom imaging system developed by Jonathan M. Bull and Martin Gutowski [2]. All the components are arranged on the tow body in such a way that the longitudinal and the vertical centres of gravity coincided with the mid sections of the body in both lateral and transverse directions. The dimensions of the buoyancy chamber are selected in such a way that the upward force due to chamber is more than the total pay load in the tow body. Buoyancy requirements are fulfilled and also checked for the longitudinal and transverse stability. The body is positively buoyant which floats at half draft so that the transmitting face of the projector and all the hydrophones of the system are always underwater during the trials. The buoyancy chamber which is used to give the required buoyancy is made from polyurethane foam which is tightly coated with a GFRP laminate and all the properties of the P.U. foam and the FRP laminate are given in Table -1.

Water absorption test on the FRP laminate are done as per ASTM standards D570 [3], a standard test method for water absorption on plastics and the material and passed the test with zero percentage of water absorption. The entire body is covered using aluminium frames for giving added rigidity during towing and transportation. 
Table -1: Properties of P.U. Foam and FRP Laminate

\begin{tabular}{|l|l|l|}
\hline Properties & $\begin{array}{l}\text { P.U. } \\
\text { Foam }\end{array}$ & $\begin{array}{l}\text { FRP } \\
\text { Laminate }\end{array}$ \\
\hline Density $\left(\mathrm{kg} / \mathrm{m}^{3}\right)$ & 60 & 1,480 \\
\hline Water absorption $(\%)$ & $1.5-5$ & Zero \\
\hline Tensile Strength (MPa) & $1-69$ & 170 \\
\hline Tensile Modulus (MPa) & $69-690$ & 11,420 \\
\hline $\begin{array}{l}\text { Flexural Strength at yield or } \\
\text { break }\end{array}$ & $5-31$ & 200 \\
\hline
\end{tabular}

After fabrication, the body is tested for its kinematics in the towing tank facility at IIT Madras. Initially the body is towed and tested in the towing tank safely till a speed of $2 \mathrm{knots}$. It is observed that the diamond shaped bow resulted in the bow mounting of the body above $3 \mathrm{knots}$, and resulted in increase of drag force drastically.

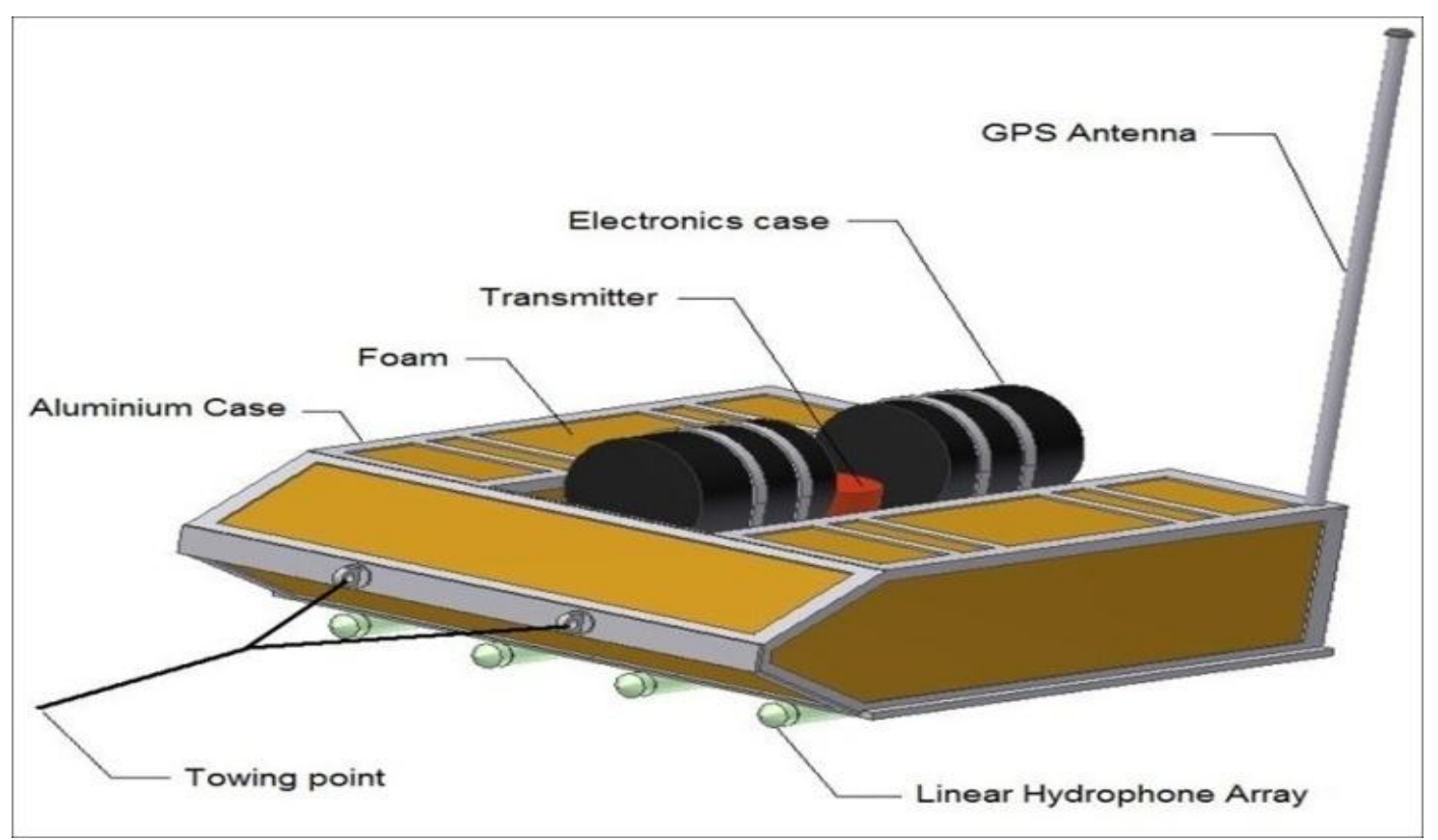

Fig -1: Perspective view of Tow body and its components

\section{FORCE ANALYSIS OF THE INITIAL BOW GEOMETRY}

A theoretical force analysis is carried out to identify the reason for the bow mounting phenomenon when towed above a speed of 2 knots. The tow body is floating at a half draft of $150 \mathrm{~mm}$ before tow, so that the upper slant face of the diamond bow is completely above water surface. The weight of the body is balanced by the buoyant force and the body is stable at half draft, till the body is towed up to a speed of 2 knots. When the towing speed crossed a limit of 2 knots, water slowly started impinging on to the upper slant surface of the tow body and caused drooping down of the bow.. Initially a force analysis has been done analytically with the present geometry and calculated the forces on the body due to the resistance of water at a speed of $2 \mathrm{~m} / \mathrm{s}$.

It is understood from the Fig -2 that the vertical component of the normal force to the bottom slant surface, $F_{n b}$, which is acting in the upward direction is balancing the floating towed body till it floats at half draft. Water impingement on the body resulted in another downward vertical component of the normal force to the top slant surface, $F_{n t}$, which is a function of the angle of the slant surface, $\theta$ with the horizontal. In this geometry, angle of the slant surface is $25.50^{\circ}$ and the maximum value of the vertical component of the force is estimated as $245 \mathrm{~N}$ when it is fully submerged. Different forces coming on the initial geometry while towing at $2 \mathrm{~m} / \mathrm{s}$ is shown in Fig -2 . 


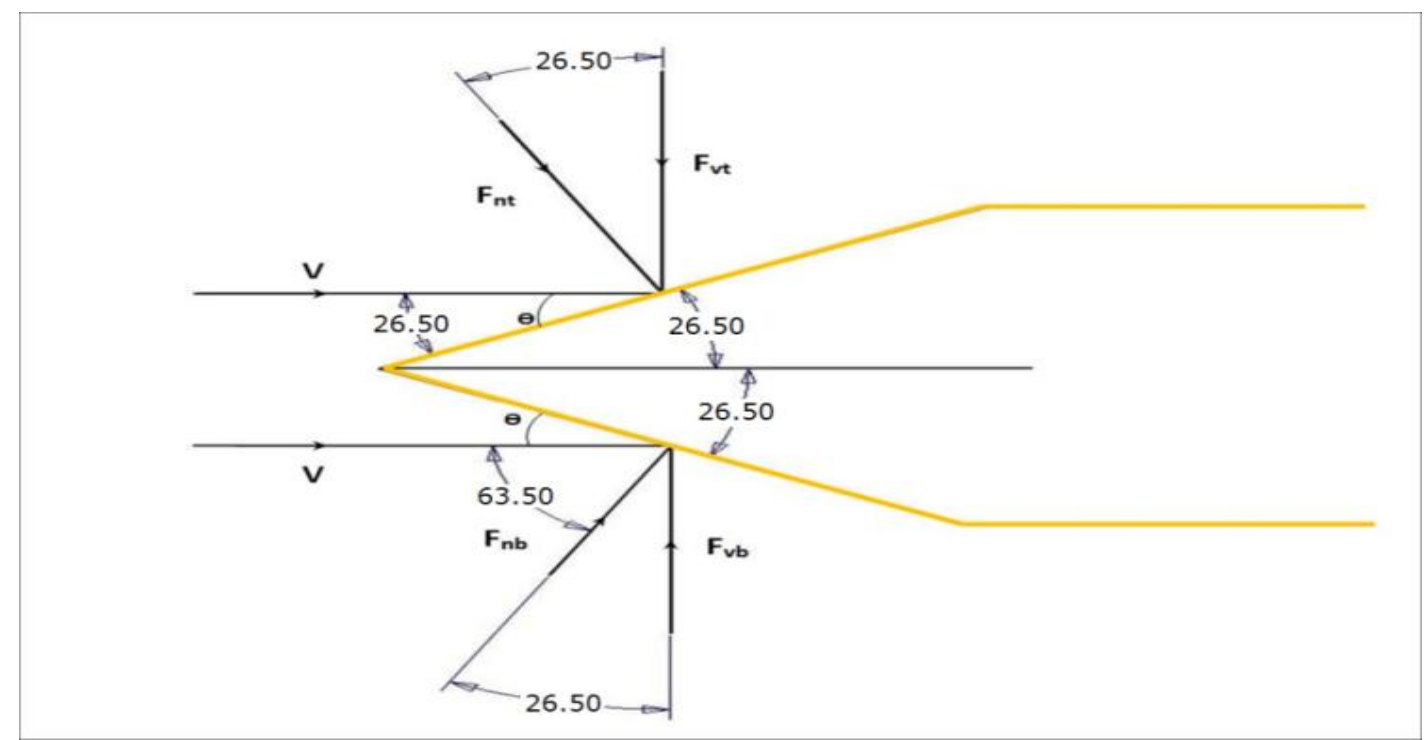

Fig -2: Different forces on the initial geometry while towing @ $2 \mathrm{~m} / \mathrm{s}$

Here the density for the impinging fluid $(\rho)$ is assumed to be $1025 \mathrm{~kg} / \mathrm{m}^{3}$ as the medium of usage for the tow body is sea water and velocity of impinging fluid is taken as $2 \mathrm{~m} / \mathrm{s}$.

The total vertical force on the top and bottom surfaces can be estimated [4] from the below expression,

$$
F_{v t}=\rho a V^{2} \sin \theta \cdot \cos \theta
$$

So, a total vertical downward force of $245.53 \mathrm{~N}$ is acting on the upper slant surface and an equal amount of force is acting in the upward direction. When the upward force is balanced by the weight of the body, the downward vertical force became uncompensated and is the cause for drooping down of the tow body.

\section{CFD ANALYSIS OF THE INITIAL GEOMETRY}

Objective of this analysis is to study the effect of the bow shape on the bow mounting phenomenon (drooping down of the bow) and to compare with the theoretical results. For the analysis, it is assumed that the body is stationary and is fully immersed in water. In general a body accelerating in a still fluid is not equivalent to an accelerating fluid past a stationary object [5]. But here, the surrounding water mass is made to flow at the required speed of $2 \mathrm{~m} / \mathrm{s}$ in the opposite direction so that the real conditions can approximately generated for the analysis. Commercially available CFD software, Fluent is used to validate the calculated results. Contours of static pressure generated on the surfaces of the tow body are plotted in Fig -3 and the observations are listed in Tables -2 and 3.

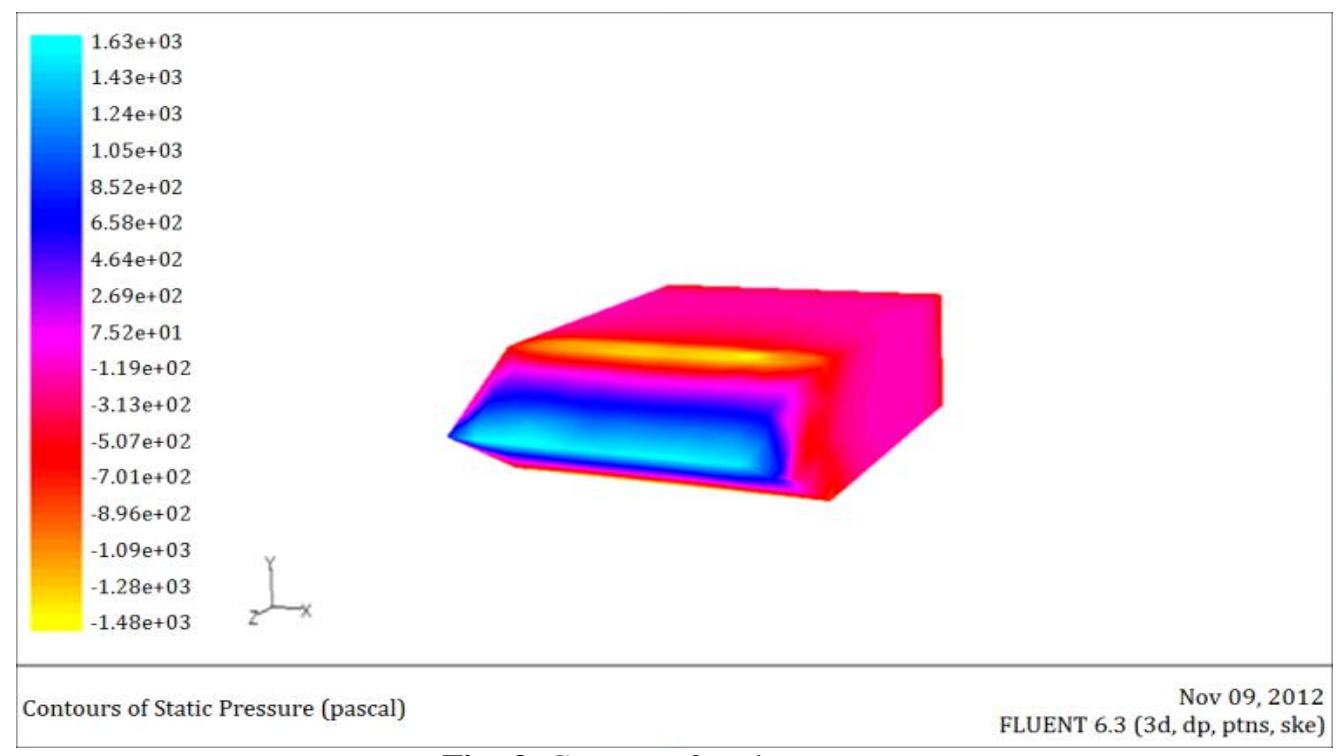

Fig -3: Contour of static pressure 
Table -2: Force vector: $\left(\begin{array}{lll}0 & -1 & 0\end{array}\right)$

\begin{tabular}{|l|l|l|l|}
\hline $\begin{array}{l}\text { Zone } \\
\text { name }\end{array}$ & $\begin{array}{l}\text { Pressure } \\
\text { force, } \\
(\mathbf{N})\end{array}$ & $\begin{array}{l}\text { Viscous } \\
\text { force, } \\
(\mathbf{N})\end{array}$ & $\begin{array}{l}\text { Total } \\
\text { force, } \\
(\mathbf{N})\end{array}$ \\
\hline Top slant & 160.499 & -2.021 & 158.477 \\
\hline Net & 160.499 & -2.021 & 158.477 \\
\hline
\end{tabular}

Table -3: Force vector: $\left(\begin{array}{lll}0 & 0 & 1\end{array}\right)$

\begin{tabular}{|l|l|l|l|}
\hline $\begin{array}{l}\text { Zone } \\
\text { name }\end{array}$ & $\begin{array}{l}\text { Pressure } \\
\text { force, } \\
(\mathbf{N})\end{array}$ & $\begin{array}{l}\text { Viscous } \\
\text { force, } \\
(\mathbf{N})\end{array}$ & $\begin{array}{l}\text { Total force, } \\
(\mathbf{N})\end{array}$ \\
\hline Back & -215.065 & 0 & -215.065 \\
\hline $\begin{array}{l}\text { Bottom } \\
\text { slant }\end{array}$ & -73.386 & -3.944 & -77.331 \\
\hline Top slant & -80.022 & -4.055 & -84.077 \\
\hline Net & -368.474 & -7.999 & -376.473 \\
\hline
\end{tabular}

Based on the observations from the analysis results, it is found that the top slant face in the tow body made at an angle of $26.5^{\circ}$ is the reason for the increase in the drag and the drooping down of the tow body with its bow. So, to minimize the drag and to avoid the bow mounting, the bow has been modified based on the analysis and experimental results.

\section{MODIFIED TOW BODY}

Tow body along with transducers and electronics is required to move without turbulence and other disturbances to the water for making the acoustic measurements with the desired accuracy. Effects of turbulence on shallow water imaging systems are reported earlier by Henyey et al [6]. So, the bow of the body has been modified to a cross bow shape to minimize the drag as well as to avoid the bow mounting phenomenon. The length of the body has been increased to $1.75 \mathrm{~m}$ and width is reduced to $0.7 \mathrm{~m}$ in order to give a hydrodynamic shape to the body for an increase in the stability. The indigenously developed acoustic transmitter, which is placed in the middle of the initial design has been shifted to the front side of the body in order to reduce the spacing between the linear hydrophone arrays. GPS Antenna module along with its mast is shifted to the centre of the body in order to give more stability to the body while towing in the wave conditions. The meta-centric height, GM of the body is brought to a value of $1.1 \mathrm{~m}$ to achieve a good stability in rolling. For a floating body, as the distance between meta-centre and the centre of gravity (GM) increases period of roll will comes down based on the expression given below [7].

Roll natural period of a floating body is

$$
T_{r}=2 \pi \sqrt{\frac{\mathrm{M} \times \mathrm{r}_{44}^{2}+\mathrm{A}_{44}}{\rho \mathrm{gVG} \mathrm{M}_{\mathrm{T}}}}
$$

where $\mathrm{M}$ is total mass including pay load; $\mathrm{r}_{44}$ is the roll radius of gyration with respect to an axis parallel with $\mathrm{x}$-axis through the centre of gravity; $\mathrm{A}_{44}$ is the roll added moment; $\mathrm{GM}_{\mathrm{T}}$ is the distance from Center of Gravity (C.G.) to metacentre; $\mathrm{V}$ is the volume displaced; $\rho$ is the density of water and $\mathrm{g}$ is acceleration due to gravity. Mass properties of the floating body are obtained from solid model built in Auto CAD Inventor, software for mechanical 3D solid modeling. A perspective view of the modified tow body with all the components is shown below in Fig -4.

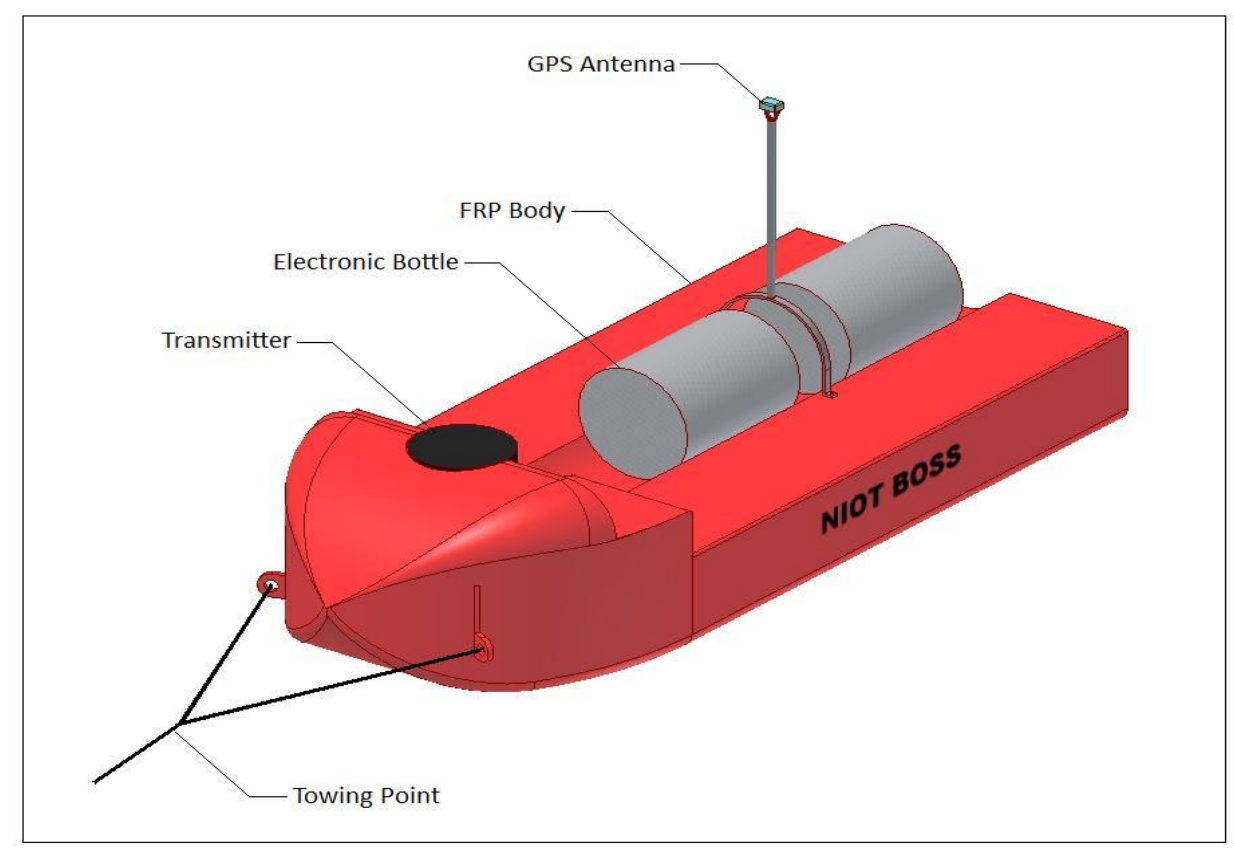

Fig -4: Perspective view of the modified Tow body and its components 
Instead of making a full length cross bow type, a half cross shape has been fabricated in the bow region as shown in Fig-5 and a towing test is conducted at different intervals of velocity (1-4 knots), with 0.5 step interval in a $85 \mathrm{~m} \times 3.2 \mathrm{~m} \times 2.5 \mathrm{~m}$ deep Towing tank facility at Indian Institute of Technology, Madras, India. An electrically driven carriage with a maximum speed of 10 knots is used to tow the floating tow body. Tow body is found safe and stable till a speed of 3 knots and it is observed that the body drooped down with its bow suddenly when the speed reached a limit of 4 knots.

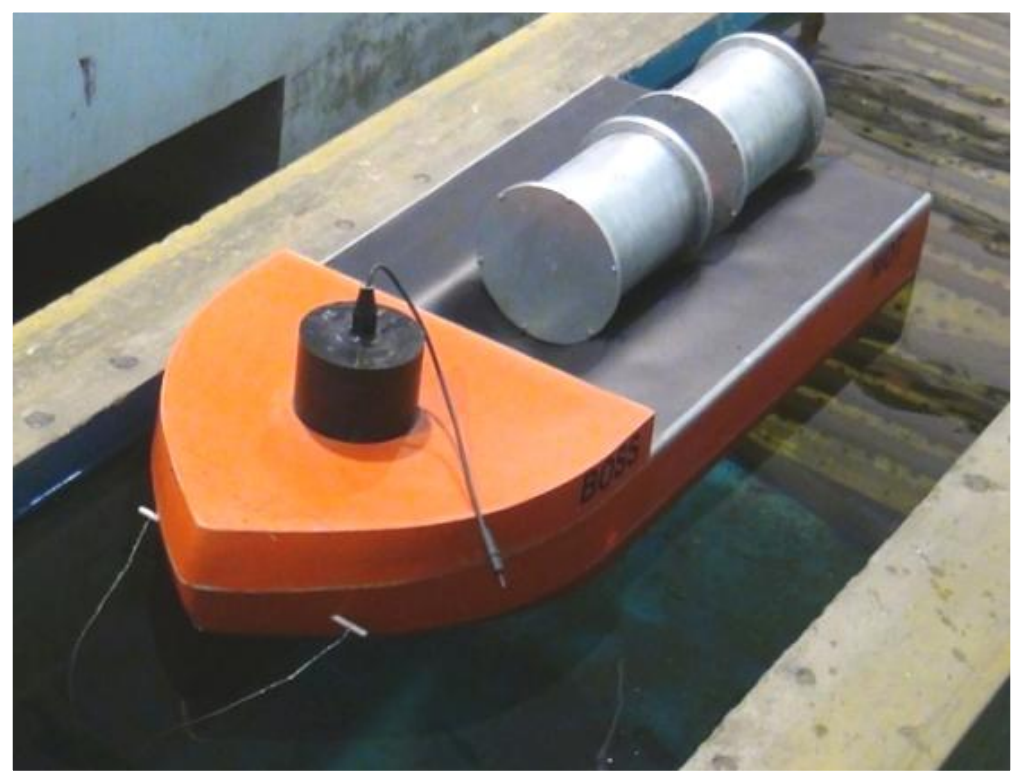

Fig -5: Tow body (Half Cross-bow)

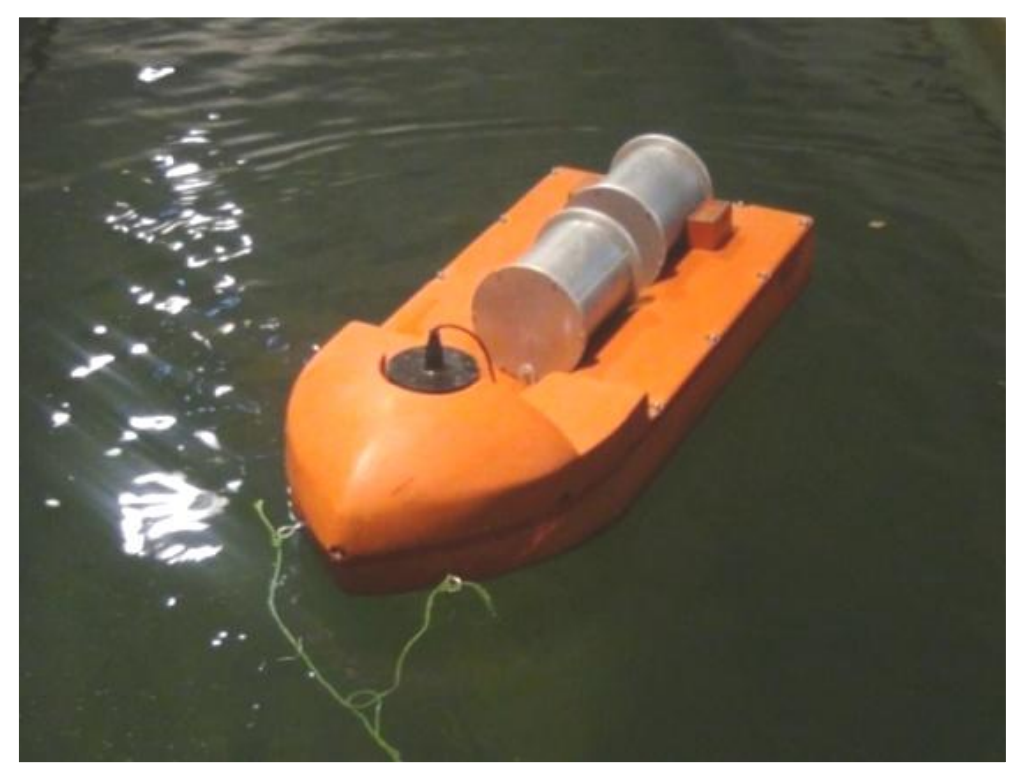

Fig -6: Modified tow body (Full Cross-bow)

So, based on the observations in the first towing test, bow of the body is modified again to a full length cross shape and tested for its kinematic behavior at different intervals of velocity (1-6 knots), with 0.5 step interval. The maximum drag offered by the body during towing is measured and found within limits. Final modified tow body with its components is shown in Fig-6.

\section{RESULTS AND DISCUSSION}

Initially bow of the tow body drooped down slowly while tested above 3 knots speed because of the diamond like shape at the bow. Tow body has again shown the same tendency to bow at a speed of around 4 knots even with the modified bow of half cross bow shape. In view of these tow test results, the bow of the floating tow body has been modified to a full length cross bow shape and towing test are conducted at different intervals of velocity (1-6 knots), with 0.5 step interval. A steady towing behavior is observed even at higher speeds and the maximum drag offered by the body at 6 knots is around $280 \mathrm{~N}$. A plot between resistance and towing speed is shown in the Chart-1. 


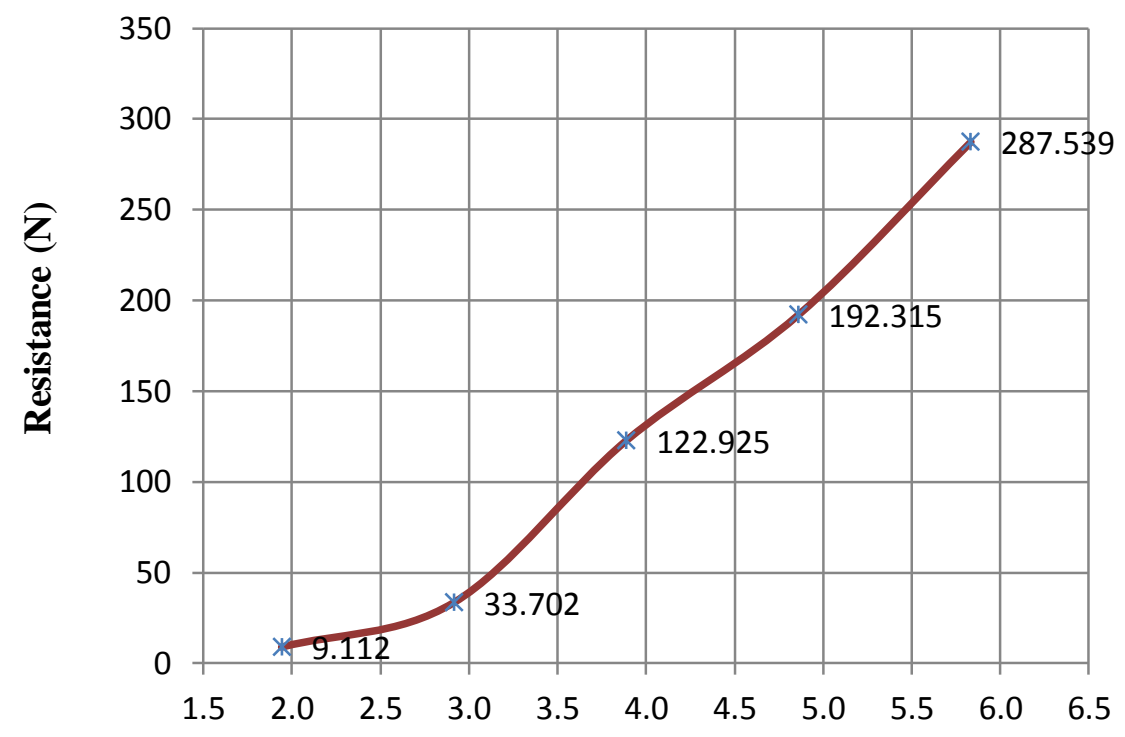

Towing Speed (knots)

Chart -1: Drag force at different tow speeds

It can be observed from the graph that the drag is very minimum up to a speed of 3 knots. There is a sudden growth in the drag from 3 to 4 knots even though the magnitude is marginal. This is due to the splashing of water above the half draft line of the body when speed crosses a limit of 3 knots. So, it is preferable to use the tow body at a speed of $3 \mathrm{knots}$, though the body can be safely towed up to a speed of 6 knots.

In the situation of a floating body drag force depends on the shape and size of the moving body and the flow direction. An approximation for the drag force can be given by the expression shown below [4].

$$
F_{D}=\frac{1}{2} \times \rho \times A \times C_{d} \times V^{2}
$$

Based on the above expression, the maximum drag force at 4 knots speed can be approximated as $115 \mathrm{~N}$ theoretically. It can also be seen from the above plot that the drag force offered by the body at 4 knots is around $112 \mathrm{~N}$ which is almost in agreement with the theoretically calculated value.

\section{CONCLUSION}

In this paper the summary of the development of a $94 \mathrm{~kg}$, $1.75 \mathrm{~m} \times 0.70 \mathrm{~m} \times 0.30 \mathrm{~m}$ stable floating tow body is presented. A turbulent free towing of the tow body is required for the operation of scanning SONAR. Bow shape of the body has a predominant role to play on the stable towing and the kinematic behavior of a floating tow body. A cross shape type bow is adopted at the bow side of the floating tow body for minimizing the drag as well as the turbulence of the body during the tow. The dimensions are selected such that it gives a streamlined shape of the body. Both the size and shape of the body has been finalized after several experiments and iterations. It is successfully tested for its kinematic behavior at different intervals of velocity (1-6 knots), with 0.5 step interval and also measured its drag at different level of speed. In addition to the towing tank tests, it has also been tested in the real sea conditions successfully.

\section{ACKNOWLEDGEMENTS}

The authors are grateful to all the members of Marine Sensor Systems group, NIOT as well as the workshop staffs of Ocean Engineering Department, IIT Madras for their keen support during the fabrication and the testing of the tow body. This work is funded by National Institute of Ocean Technology (NIOT), Ministry of Earth Sciences, Govt. of India.

\section{REFERENCES}

[1]. Robert Latorre and Jason Mims, 2000 "Development and deployment of a stable tow body", Ocean Engineering, Vol 27:203-217.

[2]. Jonathan M. Bull and Martin Gutowski, 2005 "Design of a 3D Chirp sub-bottom imaging system”, Marine Geophysical Researches, Vol 26:157-169.

[3]. ASTM D570 - 98, 2010 e1-"Standard Test Method for Water Absorption of Plastics."ASTM International, West Conshohocken, PA, 19428-2959 USA

[4]. Batchelor, G.K., 1967, "An Introduction to Fluid Dynamics", Cambridge University Press.

[5]. M.Gad-el-Hak, 1987 "The water towing tank as an experimental facility" Experiments in Fluids 5,289- 297. 
[6]. Henyey, F.S.; Rouseff, D.; Grochocinski, J.M.; Reynolds, S.A.; Williams, K.L.; Ewart, T., (2007)"Effects of internal waves and turbulence on a horizontal aperture sonar," Oceanic Engineering, IEEE Journal of , vol.22, no.2, pp.270,280.

[7]. Faltinson O M (1990), "Sea loads on ships and offshore structures", Cambridge University press.

\section{BIOGRAPHIES}

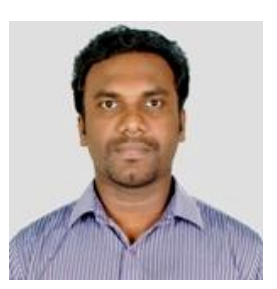

C. Kannan received his B.Tech degree in Mechanical Engineering from University of Calicut and completed his M.Tech in Ocean Engineering from Indian Institute of Technology (IIT), Madras. Presently he is working as Project scientist in Marine Sensor Systems group of National Institute of Ocean Technology (NIOT), Chennai.

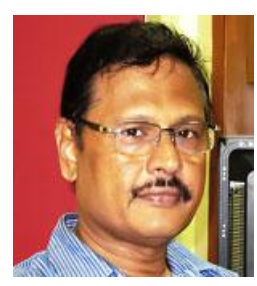

Prof. V. Ananthasubramanian received his B.Tech in Naval Architecture and Shipbuilding form Cochin University of Science and Technology in 1980. He then received his M.S and PhD from Indian Institute of Technology (IIT), Madras in 1987 and 1992 respectively. Presently he is a Professor as well as Head in the department of Ocean Engineering, Indian Institute of Technology, Madras.

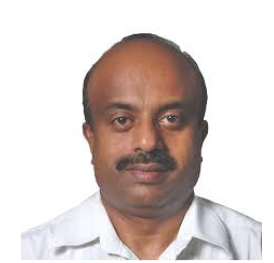

Dr. R. Dhilsha received his $\mathrm{PhD}$ in Physics from Indian Institute of Technology (IIT), Madras. Presently he is working as Scientist and Group Head of Marine Sensor Systems group of National Institute of Ocean Technology (NIOT). His area of interests include Transduction Materials, Transducer Physics, Marine sensor systems and Instrumentation

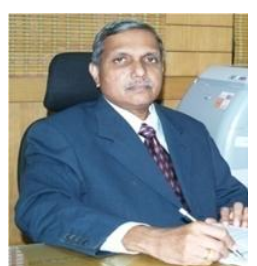

Dr. M.A. Atmanand currently the Director of National Institute of Ocean Technology and Project Director of Integrated Coastal and Marine Area Management has done pioneering work in the area of deep sea technologies in India. An Instrumentation and Control Engineer by profession, he took his undergraduate degree from University of Calicut, Master's and doctorate degrees from Indian Institute of Technology (IIT), Madras. 